\section{Cancer prevention and control: Kaposi's sarcoma}

\author{
Jackson Orem \\ Uganda Cancer Institute, Upper Mulago Hill Road, PO Box 3935, Kampala, Uganda
}

\begin{abstract}
Kaposi's sarcoma (KS) is a vascular tumour of endothelial origin that is associated with human herpes virus-8 infection. In sub-Saharan Africa, AIDS-KS remains the most common HIV-associated malignancy, and hence it poses a huge burden to the already constrained health-care systems. KS has four clinical variants, namely, classic, endemic, iatrogenic and epidemic KS. The histopathology in these different KS forms is essentially identical; however, they have different clinical patterns. Expanding knowledge of KS biology increases hope for prevention, disease control, and hence better quality of life among patients. Primary prevention strategy for KS-associated herpes virus and management of disease complication, such as lymphoedema should be the focus of disease-prevention and -control research.
\end{abstract}

Keywords: HHV8, AIDS-KS, Kaposi's sarcoma, HIV, KS, KSHV

\section{Introduction}

Kaposi's sarcoma (KS) is a multifocal angioproliferative disorder of vascular endothelium [1]. There are four clinical variants of KS: classic, endemic, iatrogenic and epidemic KS [2]). The classic form of KS was originally described by Moritz Kaposi. This is an aggressive tumour of older men of Mediterranean or Eastern European origin mainly affecting the skin. The endemic form of KS was described as early as 1963 before the advent of HIV [3]. Also called African KS, this form is aggressive and affects both adults and children. The substantial occurrence of KS in African children reflects the high level of KS-associated herpes virus (KSHV) infection in the population [4, 5]. With the emergence of HIV, the AIDS-associated KS is now the most common variant of KS in sub-Saharan Africa [6]. latrogenic or transplant associated KS is not common in Africa due to the low levels of transplants currently done on the continent, but this could become a problem in the future.

\section{Aetiology}

For decades, the aetiology and pathogenesis of KS was unknown. In 1994, Chang et al. [7], reported the discovery of the KSHV, also known as human herpes virus-8 (HHV-8), and demonstrated an etiological link between the virus and KS. KSHV induces angiogenic
Correspondence to: Jackson Orem Email: jackson.orem@uci.or.ug

ecancer 2019, 13:951 https://doi.org/10.3332/ecancer.2019.951

Published: 25/07/2019 Received: 08/11/2018

Publication costs for this article were supported by ecancer (UK Charity number 1176307).

Copyright: $($ c the authors; licensee ecancermedicalscience. This is an Open Access article distributed under the terms of the Creative Commons Attribution License (http:// creativecommons.org/licenses/by/3.0), which permits unrestricted use, distribution, and reproduction in any medium, provided the original work is properly cited. 
and inflammatory cytokines, as well as gene products implicated in angiogenesis [8]; HIV infection further potentiates the development of KS through the transactivation (Tat) protein, which acts as a growth factor for KS [9]. The Tat protein induces endothelial cell proliferation and facilitates the invasion of extracellular matrix $[10,11]$.

\section{Histopathology}

Although KS lesions may be clinically typical, biopsy of the lesion is needed for diagnosis and before patients are subjected to cytotoxic treatment. The histologic features characteristically comprise of large endothelial cells spindle shaped tumour cells. Presence of erythrocyte extravasation, inflammatory mononuclear cell infiltration, lymphocytes macrophages and plasma cells tend to be diagnostic [12]. Although the histopathology of the different types of the Kaposi tumour is essentially identical in all of these groups, the clinical manifestations and course of the disease differ dramatically $[13,14]$.

\section{Clinical presentation}

KS most frequently presents as cutaneous lesions, which may occur in any site on the body [13]. The lesions are usually linear and symmetrical following creases: They are hyperpigmented, ranging from brown to black in Africans and other shades, including pink to purple depending on race [15]. They may be flat, plaque-like or nodular and vary in size and dimensions [16]. However, absence of cutaneous lesions does not exclude visceral KS. The next site after cutaneous are oral lesions usually appearing as purple or brownish plaques on the soft palate or gingiva which are in most cases asymptomatic. They may, however, ulcerate, get infected or bleed and may be painful. Oral lesions often point to the presence of lesions in other parts of the gastrointestinal tract or viscera [17]. Gl and lung lesions are frequent sites of bleeding causing anaemia or frank haemorrhage. Pulmonary KS is a common site of extracutaneous involvement, and can be life threatening [18, 19].

\section{Diagnosis}

The most common differential diagnosis of cutaneous KS lesions in Uganda is bacillary angiomatosis; tissue evaluation is important in differentiating the two. However, microscopic features are quite similar showing abundance of proliferating mononuclear inflammatory and spindle cells, ill-defined vascular channels, haemorrhage and oedema. The best differentiator is, therefore, additional tests for KSHV DNA which is negative in bacillary angiomatosis [20]. Since the emergence of AIDS, diagnosis of KS mandates evaluation for the presence of co-existing HIV. The HIV sero-positive patient requires evaluation for opportunistic infections, and immune functions (CD4 and viral load). Initial workup for staging AIDS-associated KS involves a complete physical examination, imaging (chest X-ray, an abdominal ultrasound scan), chest X-ray in particular is useful in excluding other lung pathology and lesions, such as tuberculosis, in low-resource settings. Other tests, such as faecal blood test, complete blood count, liver function tests and renal function tests, are important basic investigations. Endoscopy or bronchoscopy may be needed in suspected pulmonary or gastrointestinal disease.

\section{Prevention and control of disease}

Currently, there is no vaccine against KSHV and no primary prevention. Given the lack of knowledge of the route of acquisition, no proper prevention message can be provided to the public. Riding on the back of the HIV prevention success, the measures in place for HIV can be used in the prevention of a KS epidemic. From an epidemiological perspective, KSHV presents a case for preventable vaccine for stopping transmission.

From the clinical perspective, since the majority of tumour cells are latently infected with KSHV, lytic replication plays a major role in disease progression and virus dissemination [21]. Therefore, transformation to lytic cycle could be a preventive strategy by increasing targets through augmented cell replication. Clinical trials to date have been negative for most inhibitors of DNA polymerase, such as ganciclovir, cidovir and foscarnet; hence, such agents should not be used outside of a study setting [22].

At a population level, a key preventive strategy would be breaking the transmission of KSHV through exchange of saliva. 


\section{Control of active disease}

Currently, KS has no cure. The goals of treatment are to control disease symptoms and prolong life, and therapy is tailored to the clinical variant of KS and disease stage. However, apart from highly active anti-retroviral therapy (HAART), treatment options are similar for the different epidemiologic forms of KS. The majority of patients with KS in sub-Saharan Africa present with advanced stage of the illness, and hence the aim of treatment is to control symptoms, palliate pain and improve their quality of life [23-25]). Surgical excision is restricted for cosmetically removing KS lesions, to alleviate discomfort. In patients with localised disease, localised treatment modalities are recommended and these include: cryotherapy, laser therapy intra-lesional chemotherapy, surgery and radiotherapy. All patients with AIDS-associated KS should initiate HAART as soon as the diagnosis is made, regardless of the CD4 T-cell counts. Treatment with HAART may induce complete remission in up to $80 \%$ of patients with good immunological response and limited disease [26]. The preferred first line chemotherapy in most low-resource countries is a combination of bleomycin and Vincristine, given every three weeks for six to nine cycles to achieve very good partial response or clinical remission. In contrast, liposomal doxorubicin is the preferred first-line regimen for AIDS-associated KS in high-income countries due to its higher efficacy and reduced toxicity [27].

Co-existing opportunistic infections, mainly TB are common among patients, with AIDS-related KS reflecting mainly the degree of immunosuppression, requiring appropriate treatment. Extensive lymphedema resulting from KSHV-induced exuberant proliferation of endothelial cells may lead to the occlusion of lymphatic vascular lumens leading to lymphedema and lymphadenopathy [28]. There is currently no clear strategy for management of lymphedema among KS patients.

\section{Conclusions}

$\mathrm{KS}$ is a vascular tumour of endothelial origin that is associated with HHV8 infection. In sub-Saharan Africa, AIDS-KS remains the most common HIV-associated malignancy and hence it poses a huge burden to the already constrained health-care systems. KS has four clinical variants, namely, classic, endemic, iatrogenic and epidemic KS. The histopathology in these different KS forms is essentially identical; however, they have different clinical patterns. Even though there is no cure at present, the expanding knowledge of KS biology increases hope for prevention and control of the disease hence better quality of life among patients with KS. Primary prevention strategy for KSHV and management of disease complication such as lymphedema should be the focus of research.

\section{Conflicts of interest}

The author has no conflicts of interest to declare.

\section{Funding declaration}

This work was supported by the Uganda Cancer Institute.

\section{References}

1. Radu O and Pantanowitz L (2013) Kaposi sarcoma Arch Pathol Lab Med 137(2) 289-294 https://doi.org/10.5858/arpa.2012-0101-RS PMID: 23368874

2. Friedman-Kien AE and Saltzman BR (1990) Clinical manifestations of classical, endemic African, and epidemic AIDS-associated Kaposi's sarcoma J Am Acad Dermatol 22(6 Pt 2) 1237-1250 https://doi.org/10.1016/0190-9622(90)70169-I PMID: 2193952

3. Lothe F (1963) Kaposi's sarcoma in Uganda Africans Acta Pathol Microbiol Scand Suppl Suppl 161 1+ PMID: 5877051

4. Chang Y, Ziegler J, and Wabinga H, et al (1996) Kaposi's sarcoma-associated herpesvirus and Kaposi's sarcoma in Africa. Uganda Kaposi's Sarcoma Study Group Arch Intern Med 156(2) 202-204 https://doi.org/10.1001/archinte.1996.00440020112014 PMID: 8546554 
5. Mayama S, Cuevas LE, and Sheldon J, et al (1998) Prevalence and transmission of Kaposi's sarcoma-associated herpesvirus (human herpesvirus 8) in Ugandan children and adolescents Int J Cancer 77(6) 817-820 PMID: 9714046

6. Parkin DM, Wabinga $\mathrm{H}$, and Nambooze S, et al (1999) AIDS-related cancers in Africa: maturation of the epidemic in Uganda Aids 13(18) 2563-2570 https://doi.org/10.1097/00002030-199912240-00010

7. Chang Y, Cesarman E, and Pessin MS, et al (1994) Identification of herpesvirus-like DNA sequences in AIDS-associated Kaposi's sarcoma Science 265 1865-1868 https://doi.org/10.1126/science.7997879

8. Ensoli B and Sturzl M (1998) Kaposi's sarcoma: a result of the interplay among inflammatory cytokines, angiogenic factors and viral agents Cytokine Growth Factor Rev 9(1) 63-83 https://doi.org/10.1016/S1359-6101(97)00037-3 PMID: 9720757

9. Fiorelli V, Gendelman R, and Sirianni MC, et al (1998) Gamma-Interferon produced by CD8+ T cells infiltrating Kaposi's sarcoma induces spindle cells with angiogenic phenotype and synergy with human immunodeficiency virus-1 Tat protein: an immune response to human herpesvirus-8 infection? Blood 91(3) 956-967 PMID: 9446657

10. Barillari $G$ and Ensoli B (2002) Angiogenic effects of extracellular human immunodeficiency virus type 1 Tat protein and its role in the pathogenesis of AIDS-associated Kaposi's sarcoma Clin Microbiol Rev 15(2) 310-326 https://doi.org/10.1128/CMR.15.2.310-326.2002 PMID: 11932235 PMCID: 118071

11. Ensoli B, Barillari G, and Salahuddin SZ, et al (1990) Tat protein of HIV-1 stimulates growth of cells derived from Kaposi's sarcoma lesions of AIDS patients Nature 345(6270) 84-86 https://doi.org/10.1038/345084a0 PMID: 2184372

12. Auten M, Kim AS, and Bradley KT, et al (2017) Human herpesvirus 8-related diseases: Histopathologic diagnosis and disease mechanisms Semin Diagn Pathol 34(4) 371-376 https://doi.org/10.1053/j.semdp.2017.04.004 PMID: 28502522

13. Tappero JW, Conant MA, and Wolfe SF, et al (1993) Kaposi's sarcoma. Epidemiology, pathogenesis, histology, clinical spectrum, staging criteria and therapy J Am Acad Dermatol 28(3) 371-395 https://doi.org/10.1016/0190-9622(93)70057-Z PMID: 8445054

14. Wahman A, Melnick SL, and Rhame FS, et al (1991) The epidemiology of classic, African, and immunosuppressed Kaposi's sarcoma Epidemiol Rev 13 178-199 https://doi.org/10.1093/oxfordjournals.epirev.a036068 PMID: 1765111

15. Taylor JF, Templeton AC, and Vogel CL, et al (1971) Kaposi's sarcoma in Uganda: a clinico-pathological study Int J Cancer 8(1) 122-135 https://doi.org/10.1002/ijc.2910080116 PMID: 5118203

16. Bayley AC (1984) Aggressive Kaposi's sarcoma in Zambia, 1983 Lancet 1(8390) 1318-1320 https://doi.org/10.1016/ S0140-6736(84)91818-X PMID: $\underline{6145025}$

17. Yoo DJ, Lee KH, and Munderi P, et al (2005) Clinical and bronchoscopic findings in Ugandans with pulmonary Kaposi's sarcoma Korean J Intern Med 20(4) 290-294 https://doi.org/10.3904/kjim.2005.20.4.290

18. Rezende RE, Kahwage RL, and da Costa TV, et al (2015) Upper gastrointestinal Kaposi's sarcoma in HIV-infected patients: ten years of endoscopy observation at a single Brazilian center Int J Infect Dis 39 110-115 https://doi.org/10.1016/j.jij.2015.09.006 PMID: 26376222

19. Aboulafia DM (2000) The epidemiologic, pathologic, and clinical features of AIDS-associated pulmonary Kaposi's sarcoma Chest 117(4) 1128-1145 https://doi.org/10.1378/chest.117.4.1128 PMID: 10767252

20. Jin YT, Tsai ST, and Yan JJ, et al (1996) Detection of Kaposi's sarcoma-associated herpesvirus-like DNA sequence in vascular lesions. A reliable diagnostic marker for Kaposi's sarcoma Am J Clin Pathol 105(3) 360-363 https://doi.org/10.1093/ajcp/105.3.360 PMID: 8602618

21. Grundhoff A and Ganem D (2004) Inefficient establishment of KSHV latency suggests an additional role for continued lytic replication in Kaposi sarcoma pathogenesis J Clin Invest 113(1) 124-136 https://doi.org/10.1172/JCI200417803 PMID: 14702116 PMCID: 300762

22. Kedes DH and Ganem D (1997) Sensitivity of Kaposi's sarcoma-associated herpesvirus replication to antiviral drugs. Implications for potential therapy J Clin Invest 99(9) 2082-2086 https://doi.org/10.1172/JCI119380 PMID: 9151779 PMCID: 508037 
23. Gantt S, Kakuru A, and Wald A, et al (2010) Clinical presentation and outcome of epidemic Kaposi sarcoma in Ugandan children Pediatr Blood Cancer 54(5) 670-674 https://doi.org/10.1002/pbc.22369 PMID: 20205254 PMCID: 2839022

24. Okuku F, Krantz EM, and Kafeero J, et al (2017) Evaluation of a Predictive Staging Model for HIV-Associated Kaposi Sarcoma in Uganda J Acquir Immune Defic Syndr 74(5) 548-554 https://doi.org/10.1097/QAI.0000000000001286 PMID: 28107226 PMCID: 5340582

25. Chalya PL, Mbunda F, and Rambau PF, et al (2015) Kaposi's sarcoma: a 10-year experience with 248 patients at a single tertiary care hospital in Tanzania BMC Res Notes 8440 https://doi.org/10.1186/s13104-015-1348-9 PMID: 26374100 PMCID: 5439227

26. Lebbe C, Blum L, and Pellet C, et al (1998) Clinical and biological impact of antiretroviral therapy with protease inhibitors on HIV-related Kaposi's sarcoma Aids 12(7) F45-F49 https://doi.org/10.1097/00002030-199807000-00002 PMID: 9619797

27. Krown SE (2014) Management of AIDS-Related Kaposi Sarcoma. Cancers in People with HIV and AIDS (Springer) pp 139-152 https://doi. org/10.1007/978-1-4939-0859-2_10

28. Feller L, Masipa J, and Wood N, et al (2008) The prognostic significance of facial lymphoedema in HIV-seropositive subjects with Kaposi sarcoma AIDS Res Ther 52 https://doi.org/10.1186/1742-6405-5-2 PMID: 18226270 PMCID: 2275292 